\title{
Research on direct power and torque with space vector modulation for a Dual-PWM converter
}

\author{
Huaqiang Zhang ${ }^{\mathrm{a}}$, Xiujing Qin and Fanhua Meng \\ Department of Electrical Engineering, Harbin Institute of Technology at Weihai, Weihai 264209, China
}

\begin{abstract}
This paper proposes an integration control algorithm with DPTC-SVM for a DualPWM Converter to optimize the parameters of the rectifier and inverter. The control algorithm utilizes direct power control for the PWM rectifier and direct torque control for the PWM inverter. Compared with the traditional DPTC control algorithm and DPTC-SVM algorithm, the stability of the system was analyzed by adding power feed forward loop. The rapid dynamic response and anti-interference ability are improved with the proposed algorithm, though the capability of the DC-link capacitor decreases. With TMS320LF2407 DSP platform to carry out physical verification of the induction motor current, torque and flux characteristics. Simulation and experimental demonstrations are presented to show that the input-output power matches well and the algorithm fullfill the unity power factor conditions.
\end{abstract}

Keywords: direct power and torque control; space vector modulation; dual-PWM converter; power control loop; virtual flux.

\section{Introduction}

Most rectifiers in traditional AC/DC/AC converters use a diode bridge circuit. There are some disadvantages such as low power factor, high level of input current harmonics, and high waste of regenerative energy [1]. In this regard, we put forward reversible single-phase to single-phase DC-link converters, they are composed of paralleled rectifiers and inverters sharing two legs with two dc-links. This single-phase to single-phase converters with a single DC-link circuit is shown in Figure 1.

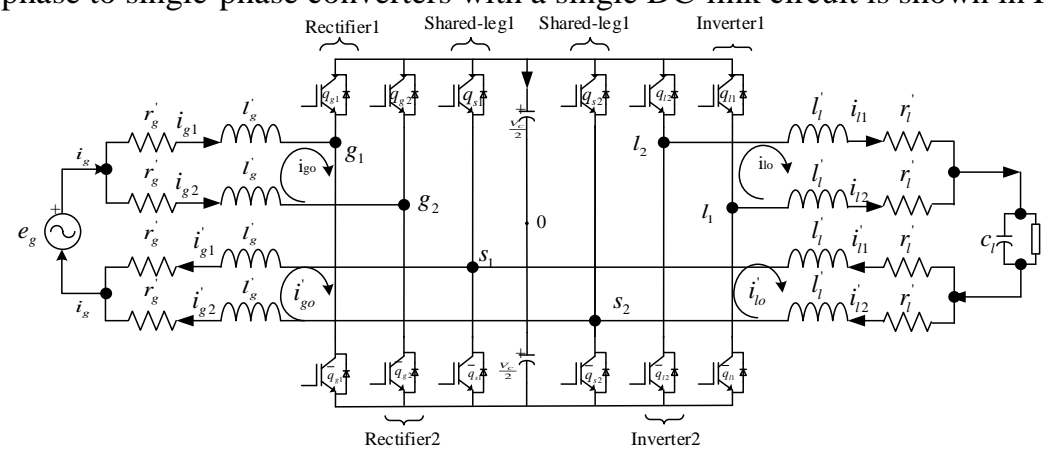

Figure 1. The single-phase to single-phase converters with a single DC-link circuit

\footnotetext{
${ }^{\text {a }}$ Corresponding author : zhq@hit.edu.cn
} 
With the development of the control methods for rectifiers and the control strategy with Pulse Width Modulation (PWM), a dual-PWM converter is common used to the adjustable speed application occasions of energy regeneration. This converter decrease: (i) the number of switches rectifiers and inverters, (ii) the input side of the harmonic content of the output transducer, (iii) the DC-link capacitors loss.

The PWM rectifier operates by using the voltage-oriented control (VOC) [2] and direct power control (DPC) [3]-[5] algorithms. The line voltage, current, and DC-link voltage of the PWM rectifier need to be detected in the VOC algorithm. Although the DPC is simple and fast dynamic response, disadvantage is that variable switching frequency and reactive power section is not controllable. The PWM inverter operates by using the field-oriented control (FOC) [6] and direct torque control (DTC) [7] algorithms. A complex coordinate transform is required, and FOC leads to slow dynamic response. Furthermore, the FOC algorithm largely depends on the parameters of the induction motor. High flux and torque ripples appear owing to its variable switching frequency.

In order to avoid the disadvantages of the conventional converter control algorithm, an integration control algorithm by using direct power and torque with space vector modulation (DPTC-SVM) is presented. An additional feed-forward power control loop (PF) is proposed to match the input-output instantaneous power well [8-9].

\section{Traditional DPTC control algorithm}

In the traditional DPTC control algorithm, the Insulated Gate Bipolar Transistor (IGBT) switching signals of the rectifier and inverter are generated by the proper switching table voltage vector. The control theory of the traditional DPTC is shown in Figure 2.

In the traditional DPTC control algorithm, the active $p$ and reactive $q$ powers are compared with their required values $p^{*}$ and $q^{*}$. The errors between $p^{*}$ and $p$ are controlled by the hysteresis comparator. Similarly, the stator flux and electromagnetic torque of the PWM inverter are calculated by the line voltage $U_{d c}$ and current $I_{s}$. The command flux and torque are compared with their reference values [10]. The flux and torque errors are controlled by the hysteresis comparators.

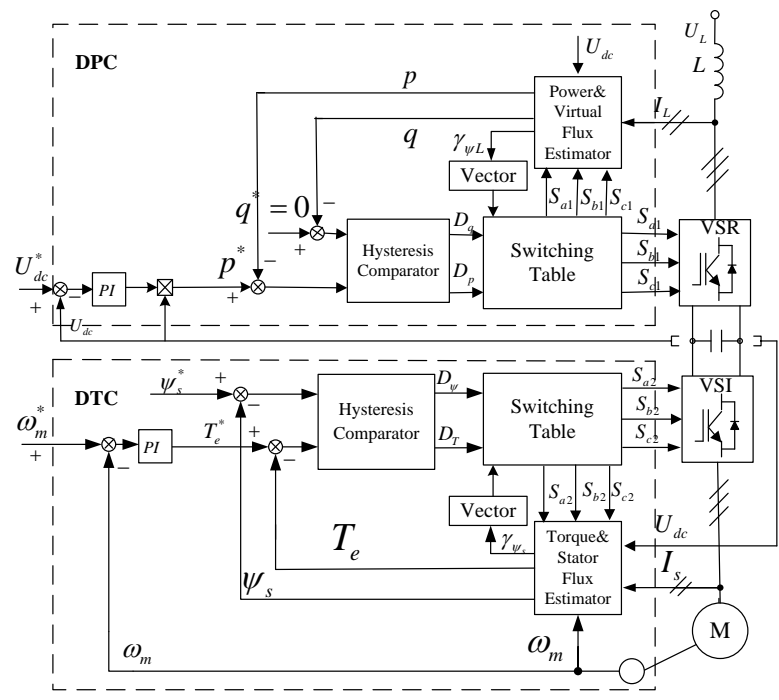

Figure 2. Control theory for the conventional DPTC

The stator flux of the PWM inverter controlled by the hysteresis comparator and switching table is expressed by 


$$
\psi_{s}(t)=\int\left(u_{s}(t)-i_{s}(t) R_{s}\right) d t
$$

Where $\psi_{s}(t)$ is the stator flux, $u_{s}(t)$ is the stator voltage, $i_{s}(t)$ is the stator current, and $R_{s}$ is the resistance of the stator phase windings.

When the motor is running at high speed, the resistance of the stator phase windings can be ignored. Then, (1) can be written as

$$
\boldsymbol{u}_{s}(t) \approx \frac{d \psi_{s}(t)}{d t}
$$

From (2), Changes stator flux is involved with the voltage space vector generated by inverter. During the time over which the voltage space vector works, the flux moves in the direction of the voltage space vector and generates an increment $\Delta \psi$. The stator flux track is nearly circular and appears a few of ripples. Thus, it leads to large torque ripples and poor performance at low speed.

\section{DPTC-SVM control algorithm}

Considering this disadvantage of the conventional DPTC algorithm, linear PI controllers instead switching table and the hysteresis controller [11-13]. The control theory for DPTC-SVM is shown in Figure 3.

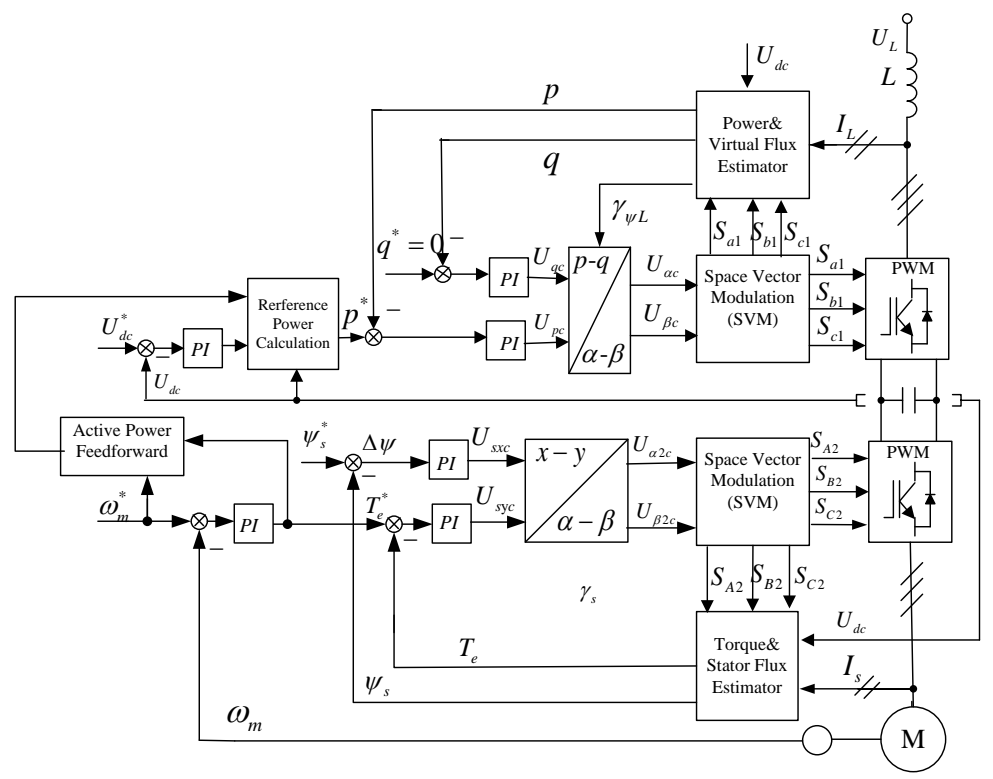

Figure 3. Control theory of DPTC-SVM

\subsection{DPC-SVM algorithm}

A line current $I_{L}$ on the input of the rectifier is deduced by voltage $U_{\mathrm{I}}$ drop across the input inductance. The input equation is written:

$$
U_{L}=U_{I}+U_{s 1}
$$

Where $U_{I}=L\left(d I_{L} / d t\right)$ is the inductance voltage, $U_{s 1}$ is voltage at the input of the rectifier, and $U_{L}$ is the line voltage. 
$U_{s 1}$ derived from DC-link voltage $U_{d c}$ :

$$
U_{s 1}=\left[\begin{array}{l}
U_{s 1 \alpha} \\
U_{s 1 \beta}
\end{array}\right]=\left[\begin{array}{l}
\sqrt{\frac{2}{3}} U_{d c}\left(S_{a 1}-\frac{1}{2} S_{b 1}-\frac{1}{2} S_{c 1}\right) \\
\frac{1}{\sqrt{2}} U_{d c}\left(S_{b 1}-S_{c 1}\right)
\end{array}\right]
$$

The virtual flux and measured line currents can be obtained from

$$
\Psi_{L}=\left[\begin{array}{c}
\Psi_{L \alpha} \\
\Psi_{L \beta}
\end{array}\right]=\left[\begin{array}{l}
\int\left(\sqrt{\frac{2}{3}} U_{d c}\left(S_{a 1}-\frac{1}{2}\left(S_{b 1}+S_{c 1}\right)\right)\right) d t+L I_{L a} \\
\int\left(\frac{1}{\sqrt{2}} U_{d c}\left(S_{b 1}-S_{c 1}\right)\right) d t+L I_{L \beta}
\end{array}\right]
$$

Where $\Psi_{L}$ is the virtual flux, and $L$ is the inductance of the input of the rectifier.

Assuming a sinusoidal signal line voltage, $p$ and $q$ can be obtained

$$
\left\{\begin{array}{l}
p=\omega\left(\Psi_{L \alpha} I_{L \beta}-\Psi_{L \beta} I_{L \alpha}\right) \\
q=\omega\left(\Psi_{L \alpha} I_{L \alpha}+\Psi_{L \beta} I_{L \beta}\right)
\end{array}\right.
$$

The command active power $p^{*}$ is supplied from the outer PI DC-link voltage controller. To fulfill the unity power factor conditions, $q$ is set to zero. The output voltage signals, $U_{s p}$ and $U_{s q}$, of the PI controller that makes the errors as the input is transformed into the $\alpha-\beta$ stationary coordinate system. Then, the reference voltage vectors, $U_{\alpha c}$ and $U_{\beta c}$, are obtained

$$
\left[\begin{array}{c}
U_{\alpha c} \\
U_{\beta c}
\end{array}\right]=\left[\begin{array}{ll}
-\sin \gamma_{\Psi L} & -\cos \gamma_{\Psi L} \\
\cos \gamma_{\Psi L} & -\sin \gamma_{\Psi L}
\end{array}\right]\left[\begin{array}{l}
U_{s p} \\
U_{s q}
\end{array}\right]
$$

Where $\gamma_{\Psi L}$ is the angle of the VF vector in $\alpha-\beta$ stationary coordinates.

$$
\begin{aligned}
\sin \gamma_{\Psi L} & =\frac{\Psi_{L \beta}}{\sqrt{\left(\Psi_{L \alpha}\right)^{2}+\left(\Psi_{L \beta}\right)^{2}}} \\
\cos \gamma_{\Psi_{L}} & =\frac{\Psi_{L \alpha}}{\sqrt{\left(\Psi_{L \alpha}\right)^{2}+\left(\Psi_{L \beta}\right)^{2}}}
\end{aligned}
$$

\subsection{DTC-SVM algorithm}

The DTC-SVM algorithm uses linear PI controllers to control the flux and torque directly, and the required switching attributes for the inverter are produced by the SVM [14-16]. In $\alpha-\beta$ stationary coordinates, the electromagnetic torque is

$$
T_{\mathrm{e}}=p_{\mathrm{b}} \frac{m_{s}}{2} \frac{L_{m}}{L_{r}} \psi_{r} I_{s} \sin \gamma
$$

Where $p_{\mathrm{b}}$ is the number of pole pairs, $m_{s}$ is the number of power phases, $L_{m}$ is the mutual inductance, $L_{s}$ is the stator inductance, $\psi_{r}$ is the rotor flux amplitude, $I_{s}$ is the stator current, and $\gamma$ is the angle between the rotor current and the stator flux vectors. 
The amplitude of the stator and rotor flux we assume is constant. Then, the torque can be controlled by changing the angle between the rotor and stator flux vectors. From (10), $T_{\mathrm{e}}$ is expressed as

$$
T_{\mathrm{e}}=p_{\mathrm{b}} \frac{m_{s}}{2} \frac{L_{m}}{L_{r} L_{s}-L_{m}^{2}} \psi_{r} \psi_{s} \sin \delta
$$

Where $\delta$ is the angle between the rotor and stator flux vector. The stator flux can be expressed by

$$
\psi_{s}=\frac{L_{m}}{L_{r}} \psi_{r}+\sigma L_{s} I_{s}
$$

Where $\sigma=1-L_{m}^{2} / L_{s} L_{r}$ is the leakage factor.

\subsection{Integration control algorithm of the PWM rectifier and inverter}

In order to reduce the DC-link voltage ripples in AC/DC/AC converters, the size of the capacitor should be increased [17]. Hence, an integration control algorithm for the PWM rectifier and inverter is developed and shown in Figure 4.

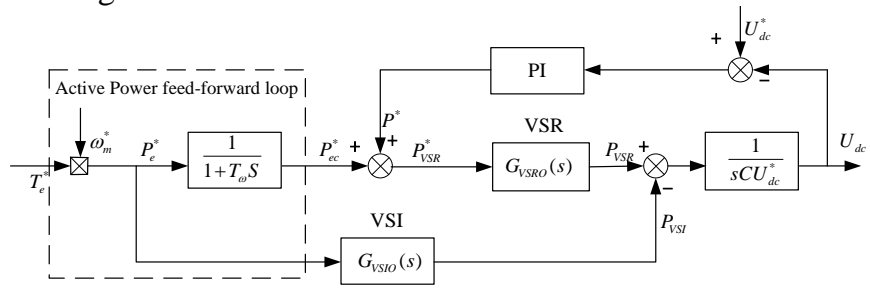

Figure 4. Control diagram of the power feed-forward loop

Ignoring the converter power loss problem, the overall active power of the PWM rectifier $P_{V S R}^{*}$ is provided energy storage for the change of the DC-link capacitor and the inverter output power $P_{V S I}^{*}$

$$
P_{V S R}^{*}=P^{*}+P_{V S I}^{*}
$$

Ignoring the resistances loss, the active power of the PWM inverter $P_{V S I}^{*}$ is supplied to the AC motor for generating electromagnetic torque. The electromagnetic power can be written as

$$
P_{e}=T_{\mathrm{e}} \omega_{m}
$$

Where $\omega_{m}$ is the rotor mechanical angular speed, and $T_{\mathrm{e}}$ is the electromagnetic torque.

The required electromagnetic power $P_{e}^{*}$ is calculated by the required values for the electromagnetic torque $_{T_{e}^{*}}$ and rotor mechanical angular speed $\omega_{m}^{*}$

$$
P_{e}^{*}=T_{e}^{*} \omega_{m}^{*}
$$

In order to satisfied the system stability condition, the $T_{\omega}$ delay should be considered. From (15), the required electromagnetic power $P_{e c}^{*}$ is expressed as

$$
P_{e c}^{*}=\frac{1}{1+T_{\omega} S} P_{e}^{*}
$$


Where $T_{\omega}$ is a dynamic time constant electromagnetic torque.

$$
P_{V S R}^{*}=P^{*}+P_{e c}^{*}
$$

The resistances losses of the converter can be neglected, considering the system delay. From (18) and (19), the input power open loop transfer function is

$$
\begin{gathered}
G_{V S R O}(S)=\frac{P_{V S R}}{P_{V S R}^{*}}=\frac{1}{1+T_{I T} s} \\
G_{V S I O}(S)=\frac{P_{V S I}}{P_{e}^{*}}=\frac{1}{1+T_{I F} s}
\end{gathered}
$$

Where $P_{V S R}$ and $P_{V S I}$ are the fact power of rectifier and inverter, respectively, $T_{I T}$ is the time constant of the rectifier power, $T_{I F}$ is the time constant of the inverter power.

\subsection{Analysis of the system stability with the PF}

The stability of the system cannot be affected by an appropriate feed-forward loop. From Figure 4, converter open loop transfer function is:

$$
G_{A O}(S)=\frac{U_{d c}}{T_{e}^{*}}=-\frac{\omega_{m} T_{I U}\left(1+s T_{U}\right) s^{2}\left(T_{\omega}+s T_{\omega} T_{I T}\right)}{\left(1+s T_{I F}\right)\left(1+s T_{\omega}\right) T(s)}
$$

where

$$
\begin{aligned}
T(S)= & s^{4} C U_{d c}^{*} T_{I U} T_{U}+s^{3} C U_{d c}^{*} T_{I U}\left(T_{I T}+T_{U}\right) \\
& +s^{2} C U_{d c}^{*} T_{I U}-K_{P U}\left(s T_{I U}+1\right) U_{d c}
\end{aligned}
$$

In (21), $T_{U}$ is the DC-link voltage filter time constant, and $T_{I U}$ and $K_{\mathrm{PU}}$ are parameters of the voltage PI controller.

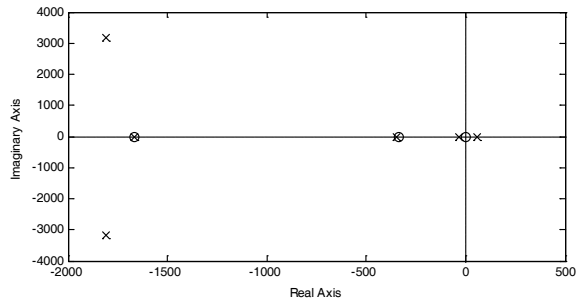

Figure 5. Zero-pole points diagram with the PF

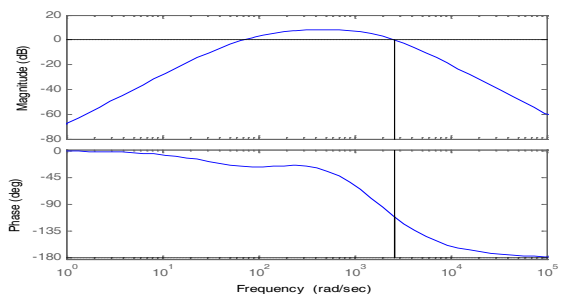

Figure 6. Bode diagram with the PF

The zero-pole points and Bode diagrams can be obtained by using the open transfer function, as shown in Figure 5 and Figure 6, respectively. The zero-pole points in Figure 5 that are near and coincide can be neglected. The main pole points are on the left side of zero. And the phase margin in the Bode diagram of the system doesn’t pass through $-180^{\circ}$.

\section{Results}

To verify the correctness and feasibility of the proposed algorithm, simulations are performed by using Matlab/Simulink. The experimental analysis is carried out based on the TMS320LF2407 DSP 
platform. The parameters of the induction motor are listed in Table 1. During the simulation, the reference stator flux amplitude is $0.9 \mathrm{~Wb}$. The switching frequency of the inverter is set at $10 \mathrm{kHz}$.

Table 1. Induction motor parameters.

\begin{tabular}{|c|c|}
\hline Parameter & Value \\
\hline Power & $55 \mathrm{~kW}$ \\
\hline Voltage & $380 \mathrm{~V}$ \\
\hline Frequency & $50 \mathrm{~Hz}$ \\
\hline Rated speed & $1430 \mathrm{rpm}$ \\
\hline Stator winding resistance & $0.0363 \Omega$ \\
\hline Rotor winding resistance & $0.073 \Omega$ \\
\hline Stator inductance & $0.0232 \mathrm{H}$ \\
\hline Rotor inductance & $0.0232 \mathrm{H}$ \\
\hline Mutual inductance & $0.026 \mathrm{H}$ \\
\hline Number of pole pairs & 2 \\
\hline Moment of inertia & $0.0131 \mathrm{~kg} \cdot \mathrm{m} 2$ \\
\hline
\end{tabular}

When the induction motor operates in the motoring mode, the reference rotating speed is $500 \mathrm{rpm}$, and the initial value of the reference load torque is $12 \mathrm{~N} \cdot \mathrm{m}$. When $\mathrm{t}=1 \mathrm{~s}$, the load should be set as 20 $\mathrm{N} \cdot \mathrm{m}$. When the induction motor operates in the regenerating mode, the reference rotating speed is $500 \mathrm{rpm}$. When $\mathrm{t}=1 \mathrm{~s}$, the load should be set as $20 \mathrm{~N} \cdot \mathrm{m}$. The results of the simulation and experiment are shown in Figures.7-10.
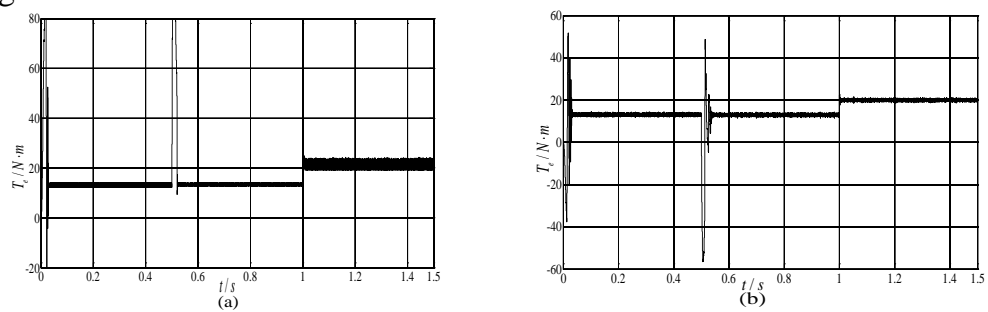

Figure 7. Waveforms for the motor torque in: (a) motoring mode and (b) regenerating mode

The electromagnetic torque responses changing from $12 \mathrm{~N} \cdot \mathrm{m}$ to $20 \mathrm{~N} \cdot \mathrm{m}$ is shown in Figure7, when $\mathrm{t}=1 \mathrm{~s}$. The simulation results show that the torque follows the required electromagnetic torque quickly.

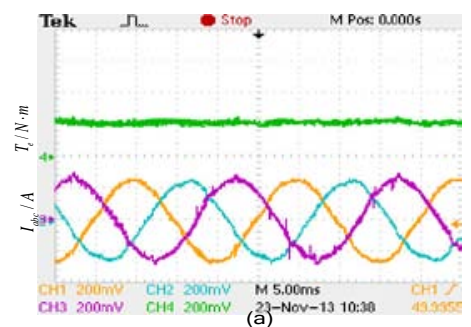

(a)

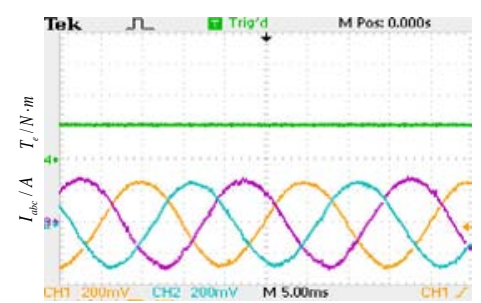

(b)

Figure 8. Waveforms for the motor torque and current: (a) the waveform using DPTC and (b) the waveform using DPTC-SVM.
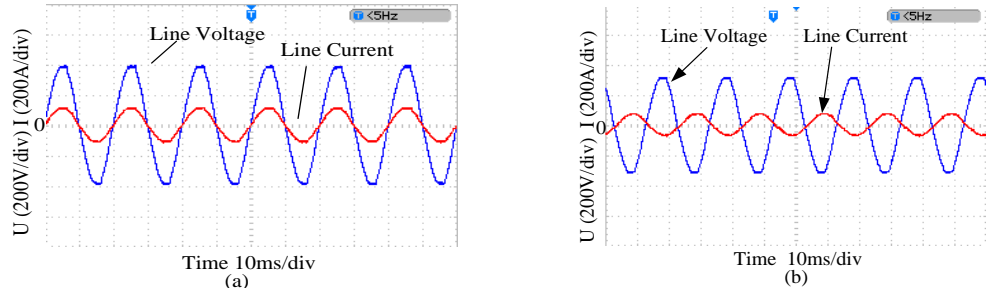

Figure 9. A phase input current and voltage of the rectifier in: (a) motoring mode and (b) regenerating mode. 
A DC motor is used as virtual load. The experimental results are shown in the following Figures. When the specific rotating speed is $1000 \mathrm{rpm}$, the load torque is $20 \mathrm{~N} \cdot \mathrm{m}$ and the motor is operating stably.

This reduces the stator flux and torque ripples. Compared DPTC-SVM with the traditional algorithm, the torque ripples is reduced by about $8 \%$ which is shown in the experimental Waveforms Figure8.

The A phase input current and voltage of the rectifier experimental results are shown in Figure 9, when motor works in motoring mode, the power factor is about 0.98. And when motor works in regenerating mode, the power factor is about -0.92. It shows that it is up to unity power factor, low total harmonic distortion (THD), and sinusoidal waveform for the line current. The experimental results are nearly the same whether it works in motoring mode or regenerating mode. And the voltage is independent of load or speed changes. So the integration control algorithm confirms the antiinterference ability of the system.

When motor works from motoring mode to regenerating mode, the experimental waveform of the motor torque and current is shown in Figure 10 (a). There is a 61\% torque overshoot in transformation statement, and the motor is operating stably within 0.1s. It's shown in Figure 10 (b) that the torque is to the steady operation within no more than $0.16 \mathrm{~s}$ at the starting period. So the system is rapid response and stabilization.
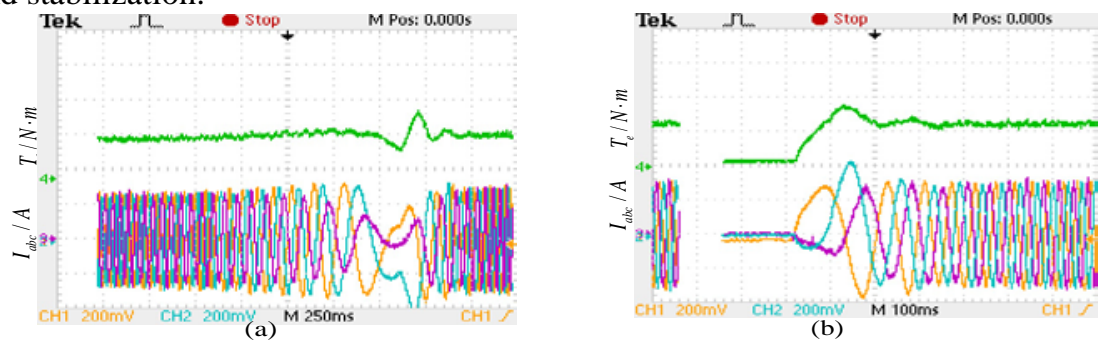

Figure 10. Waveforms for the motor torque and current: (a) statement from motoring to regenerating mode and (b) statement from shutdown to power on

\section{Conclusion}

An integration control scheme by using the DPTC-SVM algorithm is presented in this paper, which can realize no static error control of the power and torque. SVM is used to realize a constant switching frequency for a dual-PWM converter. The rapid dynamic response of the system is improved, and the active power can be transformed from the DC-link side to the inverter side efficiently. Some advantages are achieved by The DPTC-SVM algorithm compared with DPTC control algorithm traditional, such as power bidirectional flow, unity power factor, input-output power matching well, constant switching frequency for the PWM rectifier and inverter, lower current harmonics and torque ripples. The simulation and experimental results show the validity of the DPTC-SVM algorithm.

\section{Acknowledgment}

The authors thank the support both the Foundation of National Natural Science (51377168) and the Foundation of Shandong Province Science and Technology Development Planning (2011GGH20411), which enabled the achievement of the mentioned research results.

\section{References}

1. C. C. Hou and H. P. Su, IPEC, 2821-2825 (2014).

2. Q. Zhang, Z. X. Li, and Y. C. Zhang, ICEMS, 2207-2212(2013). 
3. B. Gong, K. J. Wang, J. N. Zhang, J. You, Y. H. Luo, and W. Y. Zhang, ITEC Asia-Pacific, 15(2014).

4. A. Bouafia, J. P. Gaubert, and A. Chaoui, EPE, 2-6(2013).

5. A. M. Razali, M. A. Rahman, G. George, N. Rahim, IEEE Trans. Ind. Applications., 51, 11891200(2015).

6. S. H. Rutuja and J. G. Chaudhari, ICETET, 191-194(2011).

7. J. Beerten, J. Verveckken, and J. Driesen, IEEE Trans. Ind. Electron., 57, 404-412(2010).

8. S. H. Rutuja and J. G. Chaudhari, PEDSTC, 242-248(2014).

9. X.-C. Liu, H.-G. Zhang, E.-H. Chu, and S.-J. Yan, Electr. Mach. Control, 13, 47-56(2009).

10. H. Q. Zhang, X. S. Wang, P. F. Wei, and D. G Xu, Electr. Mach. Control, 16, 13-18(2012).

11. F. Benchabane, A. Titaouine, O. Bennis, K. Yahia, and D. Taibi, Frontiers in Energy, 6, 129137(2012).

12. W. Chen, X.-D. Zou, J. Tang, Z.-X. Huang, F. Li, Z.-X. Wu, and Y.-P. Zou, Proc. CSEE, 30, 3541(2010).

13. Tey Chin Soon, Hew Wooi Ping and N. A. Rahim, STUDENT, 123-128(2012).

14. J. Marek, S. Stynski, P.Mlodzikowski, and M. Malinowski, Power Electronics for Renewable Energy Systems Transportation and Industrial Applications, 562, 319-364(2014).

15. H. Q. Zhang, F. H. Meng, and Z. P. Liang, IPEMC, 2372-2376(2012).

16. J.-H. Jiang and X.-D. Ji, Small and Special Electrical Machines, 12, 37-39(2011).

17. W. Chen, C. Chen, Z.-F. Song, and C.-L. Xia, Proc. CSEE, 29, 1-7(2009). 